\title{
Alianças Estratégicas: Conceito e Teoria
}

\author{
Marcelo Cabus Klotzle
}

\section{Resumo}

Apesar da crescente importância das alianças estratégicas nos dias atuais, pouquíssimos estudos relacionados à formação e à consolidação de parcerias nacionais e internacionais têm sido desenvolvidos no Brasil. Um dos motivos para tal deficiência é a ausência de um referencial teórico consistente, que sirva como base para o desenvolvimento de estudos empíricos sobre alianças estratégicas no Brasil. Esse artigo procura fechar essa lacuna e analisar duas teorias consideradas relevantes para o estudo de parcerias estratégicas: a teoria dos recursos empresariais e a teoria de aprendizagem organizacional. Os diversos estudos apresentados no decorrer deste trabalho, mostram que ambas as teorias parecem bem apropriadas para examinar parcerias estratégicas. Isso se deve a dois fatos: em primeiro lugar, muitas vezes tais alianças são usadas pelas empresas como forma de ganhar acesso aos recursos valiosos das parceiras. Em segundo lugar, o sucesso de uma aliança estratégia depende muito de todo o processo de transferência de conhecimentos e habilidades no decorrer da parceria.

Palavras-chaves: alianças estratégicas; teoria dos recursos empresariais; teoria da aprendizagem organizacional.

\section{Abstract}

In spite of the growing importance of strategic alliances, few studies have been done in Brazil to analyze the process of creation and consolidation of international and national strategic alliances. One of the reasons for such deficiency is the lack of a consistent theoretical basis that can be used as reference for the development of empirical works about strategic alliances in Brazil. This article tries to close this gap by analyzing two theories considered relevant for the study of strategic alliances: the Resource-Based-Theory of the Firm and the Organizational Learning Theory. The various studies presented in this article show that both theories seem appropriate to analyze strategic alliances. First because in many cases those alliances are used as means of gaining access to the valuable resources of other firms. Second because the success of an alliance depends so much on the process of transfering knowledge and abilities from one partner to another during the alliance.

Key words: strategic alliances; resource-based theory of the firm; interorganizational learning theory. 


\section{INTRODUÇÃO}

Dificilmente se passa um dia em que não haja anúncio na imprensa referente à criação ou à dissolução de uma aliança estratégica. O crescente aumento da popularidade desse novo tipo de atividade é visto como mais uma prova da constante marcha da globalização, principalmente devido ao fato de grande e crescente número desses acordos envolver empresas de, pelo menos, duas nacionalidades diferentes.

Num mundo globalizado, o incremento da competitividade tornou-se questão de sobrevivência para as empresas, independentemente do ramo em que elas atuam. A globalização não só exige presença nos mercados chaves, mas também aumento da produtividade, redução dos custos, melhoria da qualidade dos produtos, investimentos na qualificação dos funcionários e desenvolvimento de novas tecnologias; entretanto, muitas vezes, o incremento da competitividade e a onipresença em diversos mercados são atividades muito onerosas para a maioria das empresas. Poucas delas têm a capacidade de duplicar as suas cadeias de valores em tão diferentes lugares. Isso faz com que atividades de colaboração com outras empresas tenham de ser levadas em consideração, ou seja, a utilização de atividades de parceria é a maneira encontrada pelas empresas não só para sobreviverem no mercado, como também para aumentarem a sua competitividade.

A utilização de atividades de parceria com o sentido de se empreenderem relações de produção com outras firmas não é atividade recente; as inovações dos últimos tempos acontecem em pelo menos quatro níveis (Narula e Hagedoorn, 1999). Primeiro, a colaboração entre empresas é considerada agora a primeira e melhor opção, e não vista mais como a última alternativa disponível (Dunning, 1995). Segundo, as firmas estão cada vez mais usando acordos de parceria para realizarem atividades na área de Pesquisa e Desenvolvimento (P\&D), uma atividade que, tradicionalmente, foi muito vigiada pelas empresas. Cálculos recentes estimam que acordos de parceria na área de P\&D totalizam aproximadamente $10-15 \%$ de todos os acordos firmados entre empresas, e acredita-se que esse número tenha triplicado desde o início dos anos 80 (Culpan e Kostelac, 1993; Gugler e Pasquier, 1996). Terceiro, não só as firmas estão investindo em P\&D por meio de parcerias, como elas estão fazendo esses investimentos em conjunto com empresas de outros países e, muitas vezes, dentro de localidades estrangeiras (Hagedoorn, 1996). A quarta e última novidade em termos de alianças estratégicas na área de $\mathrm{P} \& \mathrm{D}$, é o crescente uso de diversas formas de organização 
não-tradicionais, em particular a crescente utilização de acordos de parceria sem participação acionária (non-equity type agreements). Em muitos casos esses tipos de acordo são o mecanismo mais eficiente de se desenvolver pesquisas em setores de alta tecnologia (Hagedoorn e Narula, 1996).

A formação de alianças estratégicas internacionais não se estende, por sua vez, somente aos países industrializados. Diversas parcerias internacionais vêm sendo feitas entre empresas multinacionais e empresas de países emergentes ou mesmo entre firmas oriundas de países em desenvolvimento (Vonortas e Safioleas, 1997).

Se observarmos o caso do Brasil, veremos que o país não é exceção. Casos como a criação da AmBev, a crescente participação de empresas estrangeiras no processo de privatização e a entrada maciça de investimentos diretos no Brasil, mostram que esse país apresenta um terreno muito fértil para a formação e o desenvolvimento de alianças estratégicas internacionais.

\section{Problema}

Apesar da crescente importância das alianças estratégicas na intensificação dos negócios internacionais competitivos de hoje, a análise científica desse tipo de parceria tem sofrido dificuldades em decorrência de dois fatores. Primeiro, existe insuficiência de trabalhos consistentes de natureza analítica, principalmente na área de modelagem, isto é, formulação de modelos relativos à criação e condução de alianças estratégicas internacionais (Vonortas e Safioleas, 1997). Segundo, existe séria deficiência em termos de documentações detalhadas acerca de casos concretos de formação e consolidação de alianças estratégicas internacionais. Essa deficiência é ainda mais acentuada quando se consideram alianças estratégicas entre empresas de países industrializados e empresas de países emergentes (Vonortas e Safioleas, 1997).

Um dos fatores críticos que dificulta a coleta e a comparação de dados, é a falta de definições universalmente aceitas sobre o que constitui uma aliança estratégica. Isto é, em parte, conseqüência da já discutida insuficiência de estudos de natureza analítica em nível internacional. Apesar de existirem exceções, como os estudos de Freeman e Hagedoorn (1995), Hobday (1995), Vonortas e Safioleas (1997) e Narula e Sadowski (1998), a insuficiência de dados e de estudos é muito aguda no caso dos países emergentes. Assim, a maior parte dos trabalhos existentes relativos às alianças estratégicas focaliza as parcerias criadas dentro de um número específico de países industrializados. Muitas vezes os resultados des- 
ses estudos são generalizados, como se fossem aplicáveis à maioria das alianças estratégicas formadas em outros países, principalmente nos países ditos emergentes. Isso representa sério déficit na área de pesquisa, principalmente se considerarmos o grande potencial das alianças estratégicas no sentido de contribuir para o desenvolvimento econômico dos países emergentes. A formação de alianças estratégicas com empresas de países industrializados permite às empresas dos países emergentes obter melhor acesso à tecnologia e aos mercados estrangeiros, além de possibilitar aos países em desenvolvimento ganhar os recursos necessários para a melhoria da infra-estrutura nacional.

Se nos concentramos no caso do Brasil, os problemas citados acima agravam-se ainda mais. Há diversas indicações de que os processos de abertura, integração e estabilização no Brasil estiveram entrelaçados com movimentos de formação de parcerias entre empresas brasileiras e empresas estrangeiras, os quais têm, aparentemente, ocorrido em escala apreciável; no entanto existem poucos estudos, como os de Arruda e Arruda $(1997,1998)$, e análises empíricas com relação ao processo de formação e desenvolvimento dessas alianças internacionais em âmbito nacional. Um fator que contribui para isso é a inexistência de estudos que visem ao desenvolvimento de referencial teórico consistente, que sirva, por sua vez, como base para a análise do processo de formação de parcerias empresariais.

\section{Objetivo}

O objetivo deste artigo é fechar essa lacuna existente e desenvolver um referencial teórico que possa ser utilizado para a elaboração de futuros estudos relacionados ao desenvolvimento de alianças estratégicas tanto no Brasil como em nível internacional. Para tal serão abordados as seguintes teorias, consideradas relevantes para o estudo de parcerias estratégicas: (1) teoria dos recursos empresariais; (2) teoria de aprendizagem organizacional.

\section{O Conceito de Aliança Estratégica}

Como já dito anteriormente, faltam definições universalmente aceitas sobre o que constitui uma aliança estratégica. Isso é, em parte, conseqüência da já discutida insuficiência de estudos de natureza analítica, em nível internacional. Esse fato faz com que diversos autores utilizem conceitos diferentes na elaboração de seus estudos que se reportam à formação de parcerias internacionais, como pode ser visto no Quadro 1. 


\section{Quadro 1: Definição de Aliança Estratégica segundo a Visão de Diversos Autores}

\begin{tabular}{|c|c|}
\hline Autor & Definição de aliança estratégica \\
\hline Teece (1992) & $\begin{array}{l}\text { Acordos nos quais dois ou mais parceiros dividem o compromis- } \\
\text { so de alcançar um objetivo comum, unindo todas as suas capaci- } \\
\text { dades e recursos e coordenando as suas atividades. Uma aliança } \\
\text { estratégica implica algum grau de coordenação estratégica e } \\
\text { operacional das atividades e inclui, entre outras, as seguintes } \\
\text { operações: atividades conjuntas de Pesquisa e Desenvolvimento } \\
\text { (P\&D), transferência mútua de tecnologia, concessão de direitos } \\
\text { exclusivos de produção e venda e acordos de cooperação na área } \\
\text { de marketing. Alianças estratégicas podem ou não envolver par- } \\
\text { ticipação acionária. }\end{array}$ \\
\hline $\begin{array}{l}\text { Hagedoorn e } \\
\text { Narula (1996) }\end{array}$ & $\begin{array}{l}\text { Alianças estratégicas podem ser classificadas de duas maneiras. } \\
\text { De um lado, existem tipos que envolvem participação acionária, } \\
\text { como joint-ventures e companhias conjuntas de pesquisa. De } \\
\text { outro lado, há formas sem participação acionária, isto é, baseadas } \\
\text { somente em contratos entre os parceiros. Nesse grupo encon- } \\
\text { tram-se, entre outros, acordos de desenvolvimento conjunto de } \\
\text { produtos, pactos de pesquisa conjunta, acordos mútuos de } \\
\text { licenciamento e contratos de Pesquisa e Desenvolvimento (P\&D). }\end{array}$ \\
\hline $\begin{array}{l}\text { Dussauge e } \\
\text { Garrette } \\
(1995,1997)\end{array}$ & $\begin{array}{l}\text { Projetos de colaboração implantados por firmas rivais, operando } \\
\text { na mesma indústria. As firmas mantêm, entretanto, a sua indepen- } \\
\text { dência. Essa definição exclui, assim, fusões e aquisições, as quais } \\
\text { levam à perda de autonomia de pelo menos um parceiro. Também } \\
\text { são excluídas parcerias verticais formadas por fornecedores e } \\
\text { compradores. }\end{array}$ \\
\hline $\begin{array}{l}\text { Lorange e } \\
\text { Roos (1996) }\end{array}$ & $\begin{array}{l}\text { Empreendimentos de risco ao longo de uma escala contínua en- } \\
\text { tre, de um lado, transações em um mercado livre (mercado) e, de } \\
\text { outro, a internalização total (hierarquia). Temos, assim, as se- } \\
\text { guintes opções de alianças estratégicas em termos do grau de } \\
\text { integração vertical com a empresa mãe: fusões e aquisições, par- } \\
\text { ticipação acionária, joint-venture, empreendimento cooperativo } \\
\text { formal e empreendimento cooperativo informal. }\end{array}$ \\
\hline Garai(1999) & $\begin{array}{l}\text { Alianças estratégicas incluem acordos de esforços conjuntos na } \\
\text { área de marketing, atividades conjuntas de Pesquisa e Desenvol- } \\
\text { vimento (P\&D), colaboração no desenvolvimento de novos pro- } \\
\text { dutos, transferência de tecnologia e atividades de terceirização. } \\
\text { Fusões e aquisições não são consideradas alianças estratégicas. }\end{array}$ \\
\hline
\end{tabular}


Ainda assim, para o pesquisador envolvido em analisar o processo de formação e consolidação de alianças estratégicas, torna-se fundamental a adoção de uma definição precisa de aliança estratégica, principalmente para evitar que esse termo tenha significados diferentes para diferentes pessoas e contextos. Conforme se vê no Quadro 1, existem autores que adotam uma visão mais restritiva de aliança estratégica, ou seja, não consideram como aliança estratégica certas relações interempresariais como, por exemplo, fusões e aquisições. Ao contrário destes, outros autores adotam uma visão mais ampla, classificando como aliança estratégica diversas formas de acordos de cooperação e parceria entre empresas.

A Figura 1 mostra as diferentes e possíveis formas que uma aliança estratégica pode assumir. A escolha dos diferentes tipos de alianças estratégicas a serem considerados em um estudo vai depender, entre outros fatores, do tipo de pesquisa adotado, do universo e da amostra a serem analisados, das limitações impostas pelo método utilizado no estudo etc.

\section{Figura 1: Tipos de Alianças Estratégicas}

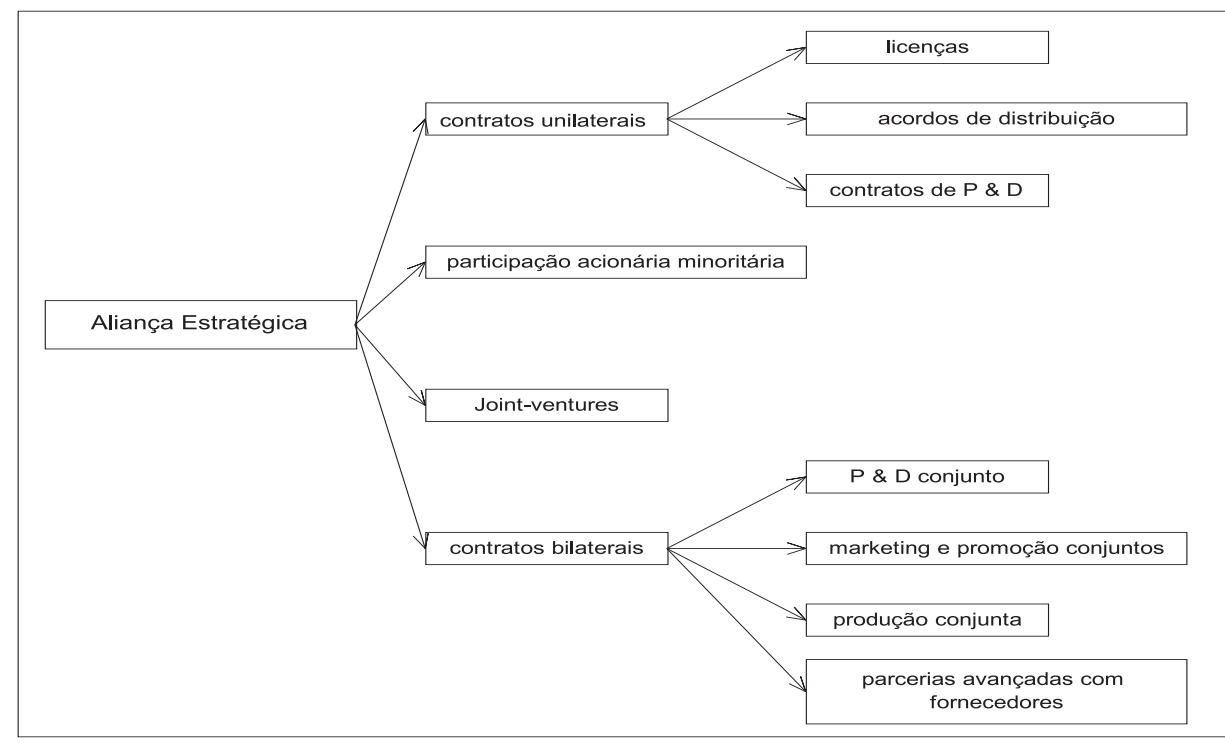

Alianças Estratégicas: Possíveis Contribuições da Teoria dos Recursos Empresariais e da Teoria de Aprendizagem OrganizaCIONAL

Nessa seção será feita a tentativa de analisar duas teorias da Administração do 
ponto de vista da sua contribuição para o desenvolvimento de um modelo, que sirva para analisar tanto a formação como o desenvolvimento de alianças estratégicas.

\section{Teoria dos Recursos Empresariais}

A teoria dos recursos empresariais surgiu recentemente como forma alternativa de se entender organizações industriais e suas estratégias competitivas. De acordo com essa visão, uma firma é equivalente ao conjunto de todos os recursos que ela possui.

Segundo Wernerfelt (1984), recursos são todos os ativos materiais e imateriais atados de forma semipermanente a uma empresa. Diferentemente das teorias tradicionais da organização industrial, que se baseiam fortemente na análise do ambiente competitivo, a teoria dos recursos empresariais tem como foco principal os recursos possuídos pela empresa, ou seja, é dada mais ênfase aos aspectos internos da empresa.

Como muitos recursos são específicos de uma empresa e não são perfeitamente móveis ou imitáveis, as firmas são muitas vezes caracterizadas por uma heterogeneidade grande em relação à sua base de recursos. A capacidade de uma empresa desenvolver uma heterogeneidade de recursos próprios se torna, portanto, uma fonte possível de vantagens competitivas que, por sua vez, podem levar a um lucro ou rentabilidade acima da média do setor ou da indústria. De acordo com essa visão, a posição competitiva de uma empresa é definida pelo conjunto de recursos e relações únicas que ela possui (Rumelt, 1984).

Uma área que continua relativamente inexplorada na literatura e pesquisa empírica é a visão das alianças estratégicas sob a perspectiva da teoria dos recursos empresariais, apesar de as parcerias estratégicas estarem continuamente aumentando em importância nos dias atuais. A teoria dos recursos empresariais parece particularmente apropriada para examinar alianças estratégicas, visto que as firmas usam tais alianças com a intenção de ganhar acesso aos recursos valiosos de outras empresas. Devido a esse motivo, os recursos de uma empresa oferecem certa base relevante para o estudo de alianças estratégicas.

Enfocando exclusivamente o processo de formação de alianças estratégicas sob o ponto de vista dos recursos possuídos pelos diferentes parceiros, Eisenhardt e Schoonhoven (1996) descobriram, por exemplo, que a tendência à formação de uma aliança é maior: (1) quando os potenciais parceiros se encontram em posições estratégicas vulneráveis (isto é, necessitam de recursos); ou (2) quando eles detêm posição forte no mercado (isto é, possuem recursos valiosos para serem divididos com outras empresas). 
Mowery, Oxley e Silverman (1998) também se basearam na teoria dos recursos empresariais para analisar a escolha de parceiros em alianças estratégicas, enfatizando principalmente o papel da capacidade tecnológica das diferentes empresas envolvidas. A sua análise dos dados se concentrou em alianças estratégicas, onde pelo menos um dos parceiros era uma empresa americana. Utilizando estatísticas relativas ao registro de patentes como meios de se avaliar a capacidade tecnológica de uma empresa, os autores chegaram à conclusão que a similaridade da capacidade tecnológica entre empresas é importante fator na decisão de escolha de parceiro para uma aliança estratégica. Os autores mostram que parceiros envolvidos tanto em parcerias nacionais como em parcerias internacionais do tipo joint-venture possuem maiores níveis de similaridade da sua capacidade tecnológica do que os ditos não-parceiros. Além disso, a congruência do nível de capacidade tecnológica dos parceiros tende a aumentar, à medida que uma aliança estratégica se vai consolidando.

Um resultado interessante da pesquisa de Mowery, Oxley e Silverman (1998) se refere à distinção entre alianças estratégicas nacionais e internacionais. Os autores descobriram maior congruência da capacidade tecnológica em jointventures formadas entre empresas americanas e não-americanas, do que em parcerias puramente nacionais. Isso mostra que os critérios utilizados por empresas americanas para selecionar os seus parceiros estratégicos internacionais são mais rígidos do que os utilizados na escolha de parceiros nacionais. Em outras palavras, para uma empresa americana escolher um parceiro internacional, esse parceiro deve mostrar nível de capacidade tecnológica maior do que o encontrado em empresas similares nos Estados Unidos.

Os autores mostram, entretanto, que a congruência extremamente grande da capacidade tecnológica entre empresas inibe a formação de alianças estratégicas, visto que não existe então nenhuma motivação para se aprender com o outro parceiro ou para se obterem recursos adicionais dele. Isso só é possível se existir certa diferenciação ou complementaridade entre os recursos das empresas envolvidas na criação de uma aliança estratégica.

Blodgett (1991) também utiliza a teoria dos recursos empresariais para analisar a formação de joint-ventures internacionais. O trabalho de Blodgett (1991) tem como objetivo determinar o papel das contribuições dos diferentes parceiros (em termos de recursos materiais e imateriais) como meio de se fazerem prognósticos sobre o percentual de cada parceiro no capital da joint-venture. Blodgett (1991) mostra que o recurso tecnologia tende a dar dominância à firma que o possui, em detrimento dos recursos relacionados aos conhecimentos do mercado local, possuídos pelos parceiros. Isso explica em muitos casos a dominância da firma estrangeira (obtenção da maioria do capital acionário) em joint-ventures formadas com firmas de países em desenvolvimento. 
Um estudo de natureza teórica que deve ser ainda mencionado nesse contexto é o trabalho de Das e Teng (2000). Os autores desenvolvem hipóteses relacionando a formação e o desenvolvimento de alianças estratégicas com os recursos possuídos pelos potenciais parceiros. Segundo eles, o mercado de recursos empresariais é imperfeito, ou seja, a troca eficiente de recursos valiosos das diferentes empresas não é possível de ser realizada no mercado livre e a vista. Certos recursos não são perfeitamente negociáveis, imitáveis ou substituíveis, já que estão incrustados nas organizações ou misturados a outros recursos. Como exemplos podemos citar a reputação de uma empresa, a sua cultura organizacional e a sua capacidade de utilização de tecnologia altamente inovadora. Devido a esse fato, alianças estratégicas são muito utilizadas como forma de se trocar, negociar ou obter acesso a esses tipos de recursos empresariais.

Das e Teng (2000) partem do pressuposto de que quanto mais os recursos de empresas forem caracterizados por mobilidade imperfeita, imitabilidade imperfeita e possibilidades de substituição imperfeita, maior será a probabilidade de essas empresas se envolverem em alianças estratégicas; por isso a posse de recursos críticos é, no conceito de Das e Teng (2000), um pré-requisito fundamental para a formação de uma aliança estratégica. Isso é comprovado por outros estudos, como o de Dollinger, Golden e Saxton (1997). Esses autores mostram que a reputação de uma potencial parceira para uma aliança estratégica, como a sua linha de produtos e a sua capacidade gerencial, exerce grande influência na escolha efetiva dessa empresa como parceira de tal aliança.

O tipo de aliança estratégica a ser escolhido pelos parceiros é também influenciado pelas características dos recursos possuídos pelas diferentes empresas. Joint-ventures, por exemplo, são o melhor instrumento para a transferência de recursos imperfeitamente imitáveis e substituíveis, principalmente devido ao alto grau de exposição entre os parceiros (Kogut, 1988). Aqui estão incluídos conhecimentos como know-how e cultura organizacional. Como se disse anteriormente, o importante é que os parceiros envolvidos tenham pelo menos certo grau de capacidade administrativa e tecnológica similar.

O problema envolvido na criação de uma joint-venture seria se a aliança se tornasse um tipo de corrida de aprendizagem, ou seja, se os parceiros iniciassem uma luta para absorver o mais rápido possível os recursos do parceiro. Das e Teng (2000) sugerem aqui como solução a criação de alianças estratégicas baseadas em acordos bilaterais, como produção conjunta, P\&D conjunto e atividades conjuntas de marketing.

Tipos de alianças estratégicas como acordos de licença, oferecem muito menos oportunidades para a transferência de tais conhecimentos. Eles são 
preferíveis para a transferência de recursos baseados em direitos de propriedade, como patentes, contratos, direitos autorais, marcas registradas e desenhos registrados.

Outro aspecto analisado teoricamente por Das e Teng (2000) é a relação entre a complementaridade e a similaridade dos recursos aportados pelos diferentes parceiros e o desempenho da aliança estratégica. Diversos estudos foram feitos nessa área; entretanto a maior parte deles não conseguiu comprovar, de maneira satisfatória, que exista relação entre os recursos dos parceiros e o desempenho da aliança estratégica internacional (Awadzi, 1987; Beamish e Banks, 1987; Awadzi et al., 1988; Harrigan, 1988; Johnson et al., 1996).

Apesar dos resultados insatisfatórios dos estudos mencionados acima, certos autores, como Das e Teng (2000), partem do pressuposto de que existe uma relação positiva entre a complementaridade e a similaridade de recursos das parceiras envolvidas em uma aliança estratégica e o seu desempenho. Por um lado, firmas não podem trabalhar juntas se elas forem muito diferentes em termos de suas culturas organizacionais, práticas de gerenciamento, orientações estratégicas e sistemas tecnológicos. Por outro lado, forças similares ou complementares dos parceiros contribuem para que haja aumento dos recursos e competências totais da aliança, aumentando com isso a sua eficiência.

Outros autores que comprovaram a importância da complementaridade dos recursos empresariais como fator determinante do desempenho de joint-ventures internacionais foram Sim e Ali (1998). Em estudo realizado com 59 joint-ventures entre empresas de Bangladesh e empresas de países industrializados e em desenvolvimento, esses autores concluíram que quanto maior o equilíbrio entre os recursos disponibilizados pelos diferentes parceiros, melhor tende a ser o desempenho da joint-venture.

Ainda no contexto da teoria dos recursos empresariais, vale a pena salientar que certos autores pressupõem uma relação entre os recursos possuídos, os riscos percebidos e os objetivos seguidos pelas diferentes empresas envolvidas em parceria estratégica.

Focando na teoria dos recursos empresariais e considerando o risco, Das e Teng (1998), por exemplo, examinaram as metas e objetivos dos parceiros envolvidos na formação de uma parceria estratégica. Segundo os autores, existe quatro tipos básicos de recursos que uma firma pode possuir e com os quais pode contribuir durante a formação de uma aliança estratégica: recursos financeiros, tecnológicos, físicos e organizacionais. Como a formação de uma parceria pode ser vista como parte de um processo no qual as firmas envolvidas procuram recursos complementares aos seus, os tipos de recursos com os quais uma firma 
contribui para a formação de uma aliança constituem fator fundamental para entender as metas e os objetivos envolvidos na sua criação.

Outro fator importante para entender o processo de formação de uma aliança estratégica é o risco. Das e Teng (1998) diferenciam entre o risco relacional e o risco de desempenho. $\mathrm{O}$ risco relacional se refere à probabilidade de que um parceiro não desenvolva um espírito de cooperação, ou seja, que adote um comportamento oportunista. O risco de desempenho, por sua vez, se refere à probabilidade de que os objetivos estratégicos acertados entre os parceiros da aliança não sejam atingidos, mesmo havendo boa cooperação entre eles.

Com base nos riscos da aliança e nos recursos possuídos pelos diferentes parceiros, os autores desenvolvem então diversas constelações, onde são feitas suposições acerca das metas e dos objetivos seguidos pelos parceiros na hora da formação da aliança estratégica. Eles argumentam, por exemplo, que em alianças com risco relacional muito alto, os parceiros que contribuem com recursos tecnológicos preferem proteger a sua tecnologia de transferências não autorizadas, limitando-se, portanto, a transferências somente de tecnologias patenteadas. Outro exemplo é dado no caso da contribuição de recursos organizacionais em uma aliança estratégica com alto risco relacional. Nesse caso, os parceiros que contribuem com tais recursos terão grande interesse em colocar seu próprio pessoal nas posições-chaves da aliança estratégica.

\section{Teoria de Aprendizagem Organizacional}

A teoria de aprendizagem organizacional encara a capacidade de aprendizagem como um dos principais fatores que influenciam a competitividade internacional de uma empresa. Segundo Osland e Yaprak (1995) a proporção e a importância relativa de indústrias baseadas no conhecimento vêm aumentando cada dia. Como conseqüência da difusão constante de novas tecnologias, o ciclo de vida de produtos e processos se tornou significativamente mais curto. Além disso, os compradores, tanto organizacionais como físicos, vêm demonstrando aumento na sofisticação da sua demanda, ou seja, vêm demandando cada vez mais produtos diferenciados e de melhor qualidade.

Nesse ambiente caracterizado por fortes instabilidades e inseguranças, a capacidade de se aprender com outras empresas e parceiros é maneira muito importante para ajudar uma firma a alcançar seus objetivos principais, como maior participação no mercado, melhor rentabilidade a longo prazo e base maior de capacidades e conhecimentos centrais. Como muitas empresas vêm aumentando a sua participação em parcerias internacionais, a teoria de aprendizagem organizacional procura demonstrar quanto é importante a transferência e a ab- 
sorção mútua de conhecimentos no processo de formação e de consolidação de alianças estratégicas internacionais.

Osland e Yaprak (1995) demonstram, por exemplo, que o maior benefício de alianças estratégicas advém do fato de elas permitirem aos parceiros aprender uns com os outros novos conceitos na área de estrutura organizacional, melhorar suas estratégias de marketing, assimilarem novas formas de cultura organizacional, além, é claro, de desenvolver novas tecnologias. Isso vai depender, por sua vez, da receptividade, da eficiência e da capacidade de absorção da empresa na área de aprendizagem organizacional. Segundo Osland e Yaprak (1995) existe pelo menos três tipos de processos de aprendizagem organizacional: imitação, grafting e sinergia.

Imitação é a tentativa de estudar estratégias, tecnologias e atividades funcionais de outras empresas e de incorporar essa experiência de segunda mão. Muitas alianças estratégicas são formadas como forma de ganhar vantagens comparativas simplesmente a partir da observação e assimilação das capacidades únicas de seus parceiros. Esse tipo de aprendizagem interorganizacional é particularmente relevante entre empresas competidoras dentro de um oligopólio. Depois que uma empresa aprendeu o que pretendia, a tendência é que ela saia da aliança e use o conhecimento adquirido para competir com o seu antigo parceiro. Hamel (1991) define esse tipo de processo de aprendizagem como colaboração competitiva.

Huber (1991) introduz o termo grafting para explicar como organizações aumentam o seu estoque de conhecimento por meio da aquisição formal de outras empresas ou pelo desenvolvimento de parcerias de longo prazo com outras empresas detentoras de conhecimentos únicos. Exemplo desse tipo de aprendizagem é a associação entre empresas multinacionais e empresas de países em desenvolvimento na forma de joint-ventures. Tais associações permitem às empresas estrangeiras obter algum conhecimento sobre a cultura local dos países nos quais estão investindo, além, é claro, obter informações sobre as práticas políticas locais. O licenciamento de produtos e processos também se encaixa dentro desse tipo de aprendizagem.

A sinergia ocorre quando firmas colaboram com o objetivo de produzir novos conhecimentos. Um exemplo é a colaboração na área de P\&D (troca de pessoal capacitado, divisão dos custos e recursos) na indústria farmacêutica e de computação. Com a colaboração os parceiros têm a possibilidade de desenvolver inovações, as quais não seriam possíveis de criar por meio de esforços independentes.

O aprendizado organizacional pode englobar qualquer um desses três processos citados anteriormente. Em todos esses três processos de aprendizado 
organizacional, a principal fonte de aquisição e obtenção de conhecimento é outra organização. Por exemplo, a NEC formou parcerias com a empresa americana Honeywell e a francesa Bull, com a intenção principal de absorver os conhecimentos desses parceiros. Essa capacidade de aprender com outros é um fator importante na posição da NEC como única firma global com um percentual forte de mercado nas áreas de telecomunicações, semicondutores e computadores.

Um estudo importante que analisou a questão do aprendizado organizacional em alianças estratégicas internacionais foi o de Tsang (1999). O principal objetivo do seu artigo foi classificar os diferentes tipos de aprendizado que ocorrem atualmente em alianças estratégicas. Segundo o autor, existe dois tipos básicos de aprendizagem: a assimétrica e a simétrica.

A aprendizagem assimétrica acontece principalmente em joint-ventures fundadas por empresas de países industrializados em países em desenvolvimento. Nesse caso existe uma lacuna muito grande de competência técnica entre os dois parceiros. Um exemplo são as joint-ventures criadas entre empresas chinesas e de Singapura. Ao passo que os parceiros chineses aprenderam a lidar com a tecnologia e assimilaram práticas mais modernas de management, as empresas de Singapura aprenderam as melhores maneiras de conduzir os seus negócios na China. A importância do aprendizado assimétrico vem aumentando dia após dia. Durante a última década milhares de empresas de países industrializados estabeleceram joint-ventures ou outras formas de alianças estratégicas em países como o Brasil, a Rússia, a China etc.

Existe, entretanto, certos riscos associados ao aprendizado assimétrico. Do ponto de vista da empresa estrangeira, existe o risco de que o conhecimento flua para o parceiro local de forma descontrolada e prejudicial, principalmente quando as leis que governam os direitos de propriedade (patentes, marcas etc.) não estão bem desenvolvidas no país anfitrião. Do ponto de vista da empresa do país em desenvolvimento, existe o risco de que o parceiro estrangeiro exagere ao estabelecer o valor do conhecimento que ele possui. O parceiro nacional pode, como resultado, pagar bem mais pelo conhecimento do que seria necessário. Outro risco se relaciona com a capacidade de absorção do parceiro local. O nível de conhecimento do parceiro local muitas vezes não é suficiente para que ele possa aprender de maneira eficiente com o parceiro estrangeiro. Isso acontece normalmente, quando a aliança estratégica atua em área onde a empresa nacional não possui vantagens comparativas.

De acordo com Tsang (1999), o segundo tipo de aprendizagem é a simétrica, que pode ser tanto mútua como não-mútua. $\mathrm{Na}$ aprendizagem simétrica nãomútua os dois parceiros têm o mesmo objetivo de aprender com a aliança estra- 
tégica, mas eles não estão efetivamente aprendendo um com o outro. Um exemplo é a formação de uma joint-venture entre dois parceiros pertencentes a um mesmo setor de baixo nível tecnológico em outra indústria ou país. Nesse caso, nenhum dos dois parceiros possui tecnologia ou vantagem competitiva que valha a pena imitar. Eles talvez se juntem com o propósito de dividir o risco e o custo de entrar em nova indústria ou país. Esse tipo de aprendizagem não foi praticamente estudado na literatura, tanto teórica como empírica (Tsang, 1999).

Pelo contrário, a aprendizagem simétrica mútua foi objeto de inúmeros estudos. Nesse tipo de aprendizagem, cada parceiro tenta absorver as competências do outro parceiro. Muitas vezes, essas competências, chamadas por Itami (1987) de ativos invisíveis, são muito caras para que os parceiros a desenvolvam sozinhos. A cooperação surge como alternativa viável para o desenvolvimento e assimilação de tais ativos. Essa forma de aprendizagem, que ocorre principalmente em indústrias de alto nível tecnológico com os parceiros vindo de países industrializados, pode ser subdividida em dois tipos: competitiva e não-competitiva.

$\mathrm{Na}$ aprendizagem competitiva, os parceiros envolvidos são competidores no mesmo mercado. Bons exemplos são oferecidos pelas alianças entre a IBM e a Apple (Gomes-Casseres, 1994), entre a General Motors e a Toyota (Adler e Cole, 1993) e entre a General Motors, Ford e DaimlerChrysler (Mano, 2000).

Por outro lado, na aprendizagem não-competitiva os parceiros não são competidores, e tampouco têm a intenção de competir no mesmo mercado em futuro próximo. Eles só pretendem melhorar suas capacidades e fortalecer suas posições nos seus respectivos mercados. Em contexto estratégico, as alianças têm caráter mais complementar do que competitivo.

Um termo muito usado para caracterizar o processo de aprendizado em parcerias estratégicas é o conceito das chamadas alianças de aprendizagem ou learning alliances. Segundo Makri (1999) alianças de aprendizagem são somente importantes caso consigam prover as empresas com informações valiosas (knowwhat), que possam ser facilmente disseminadas e absorvidas por meio da organização (know-how), para fins comerciais que aumentem a eficiência das empresas envolvidas (know-why).

Outro conceito amplamente utilizado é o termo capacidade relativa de absorção (relative absorptive capacity). Segundo Lane e Lubatkin (1998) o aprendizado deve ser encarado como processo que interage em dois sentidos, isto é, tanto do professor para o estudante e vice-versa. O aprendizado efetivo depende, por isso, da relativa similaridade entre a empresa professora e a empresa estudante.

Essa similaridade deve estender-se em pelo menos três áreas (Lane e Lubatkin, 
1998). Primeiro deve haver uma similaridade na área do conhecimento. Por exemplo, uma empresa farmacêutica que forma uma aliança estratégica com uma firma de biotecnologia deveria, em primeiro plano, possuir uma base de conhecimentos sobre bioquímica, para depois poder aprender sobre neurologia ou endocrinologia. Segundo, será mais fácil para a empresa estudante absorver novas informações, se ela possui uma política de compensação, comparável à política da professora. Políticas de compensação são importantes, porque elas exercem influência na maneira pela qual as decisões são tomadas dentro de cada empresa, o que, por sua vez, afeta o processo de aprendizagem. Terceiro, quanto maiores forem as similaridades nos objetivos comerciais, mais fácil será para a empresa estudante aplicar os conhecimentos obtidos da professora.

Lane e Lubatkin (1998) testaram suas suposições, examinando 31 alianças de P\&D entre firmas farmacêuticas e de biotecnologia no período entre 1985 e 1993. As firmas farmacêuticas foram consideradas as estudantes nessa parceria e estavam tentando obter novos conhecimentos das empresas de biotecnologia, para continuar mantendo um bom nível de descobrimento de novas drogas. Os resultados dos estudos confirmaram as suposições dos autores.

\section{Conclusões}

Apesar da crescente importância das alianças estratégicas nos dias atuais, pouquíssimos estudos relacionados à formação e à consolidação de parcerias nacionais e internacionais têm sido desenvolvidos no Brasil. Um dos motivos para tal deficiência é a ausência de um referencial teórico consistente, que sirva como base para o desenvolvimento de estudos empíricos sobre alianças estratégicas no Brasil.

Esse artigo procura fechar essa lacuna e analisar duas teorias consideradas relevantes para o estudo de parcerias estratégicas: a teoria dos recursos empresariais e a teoria de aprendizagem organizacional. Os diversos estudos apresentados no decorrer deste trabalho mostram que a teoria dos recursos empresariais parece bem apropriada para examinar parcerias estratégicas, visto que, muitas vezes, tais alianças são usadas pelas empresas como forma de ganhar acesso aos recursos valiosos das parceiras. O mesmo pode ser dito em relação à teoria de aprendizagem organizacional. Ela se mostra muito útil para a análise de todo o processo de transferência de conhecimentos e habilidades em parcerias tanto internacionais como nacionais.

A análise minuciosa das duas teorias mostra também que ambas podem ser 
combinadas em um só modelo teórico. Isso se deve principalmente ao fato de que as contribuições dos diferentes parceiros de uma aliança estratégica, em termos de recursos materiais e imateriais, só levarão a um desempenho superior da parceria, se as empresas envolvidas tiverem a capacidade de aprender umas com as outras. Só assim é possível que haja uma transferência mútua e eficiente dos diferentes recursos dentro de uma aliança estratégica. A análise de parcerias estratégicas deveria, portanto, considerar tanto os recursos materiais e imateriais, como a sua capacidade de aprendizagem. Em sentido mais amplo, a própria capacidade de aprendizagem pode ser considerada como recurso imaterial, nesse caso o mais estratégico de todos, porquanto, na sua ausência, é impossível que uma empresa assimile, de maneira efetiva, os conhecimentos de outra, o que poderia ocasionar, por exemplo, uma aprendizagem assimétrica. Isso é muito importante na análise de parcerias estratégicas, principalmente joint-ventures, entre empresas de países industrializados e em desenvolvimento. Muitas vezes há a transferência, mas não a assimilação eficiente da tecnologia por parte da empresa do país em desenvolvimento, fazendo com que as parcerias não consigam atingir um nível superior de competitividade internacional (Klötzle, 1999).

Estudos que fossem feitos em alianças estratégicas entre empresas brasileiras ou entre empresas brasileiras e estrangeiras e que procurassem integrar essas duas teorias, muito iriam contribuir para o entendimento de todo o processo de formação e gestão de alianças estratégicas no Brasil. Isso é muito importante, principalmente no caso de joint-ventures internacionais, onde existe uma grande incidência de parcerias mal-sucedidas no Brasil.

\section{ReferênCIAs Bibliográficas}

ADLER, P. S.;

COLE, R. E.

Designed for learning: a tale of two auto plants. Sloan Management Review, v. 34, n. 3, p. 85-95, 1993.

ARRUDA, M. C.;

ARRUDA, M. L.

Alianças estratégicas internacionais: formação e estruturação em indústrias manufatureiras. Revista de Administração de Empresas, v. 37, n. 4, p. 28-37, 1997.

Alianças estratégicas internacionais: desempenho e estratégias de marketing. Revista de Administração de Empresas, v. 38, n. 1, p. 27-37, 1998. 
AWADZI, W. K.

Determinants of joint-venture performance: a study of IJVs in the U.S. Louisiana, 1987. Thesis (Ph.D.) - Louisiana State University.

AWADZI, W. K. et al.

Strategic implications of cooperation and complementary resources in international jointventures. International Journal of Management, v. 5, n. 2, p. 125132, 1988.

BEAMISH, P. W.;

BANKS, J. C.

Equity joint-ventures and the theory of the multinational enterprise. Journal of International Business Studies, v. 18, n. 2, p. 116, 1987.

BLODGETT, L. L.

Partner contributions as predictors of equity share in international joint-ventures. Journal of International Business Studies, v. 22, p. 63-78, 1991.

CULPAN, R.;

KOSTELAC, E.

Cross national corporate partnership: trends in alliance formation. In: CULPAN, R. (Org.). Multinational strategic alliances. New York: International Business Press, 1993. p. 103-122.
DAS, T. K.;

TENG, B.-S.

Between trust and control: developing confidence in partner cooperation in alliances. Academy of Management Review, v. 23, p. 491-512, 1998.

A resource-based theory of strategic alliances. Journal of Management, v. 26, n. 1, p. 3157, 2000.

DOLLINGER, M. J.;

GOLDEN, P. A.;

SAXTON, T.

The effect of reputation on the decision to joint venture. Strategic Management Journal, v. 18, p. 127-140, 1997.

DUNNING, J. H.

Reappraising the eclectic paradigm in the age of alliance capitalism. Journal of International Business Studies, v. 26, n. 3, p. 461-491, 1995.

DUSSAUGE, P.;

GARRETTE, B.

Determinants of success in international strategic alliances: evidence from the global aerospace industry. Journal of International Business Studies, v. 26, p. 505-530, 1995. 
Anticipating the evolutions and outcomes of strategic alliances between rival firms (the construction, forms, and consequences of industry networks). International Studies of Management and Organization, v. 27, n. 4, p. 104116, 1997.

EISENHARDT, K. M.;

SCHOONHOVEN, C. B.

Resource-based view of strategic alliance formation: strategic and social effects of entrepreneurial firms. Organization Science, v. 7, p. 136-150, 1996.

FREEMAN, C.;

HAGEDOORN, J.

Convergence and divergence in the internationalisation of technology. In: HAGEDOORN, J. (Org.). Technical change and the world economy. Aldershot: Edward Elgar, 1995.

GARAI, G.

Leveraging the rewards of strategic alliances. Journal of Business Strategy, Mar.-Apr. 1999.

GOMES-CASSERES, B.

Group versus group: how alliance networks compete. Harvard Business Review, v. 72, n. 4, p. 62-74, 1994.
GUGLER, P.;

PASQUIER, M.

Strategic alliances of Swiss firms: theoretical considerations and empirical findings. St. Gallen: Institut für Marketing und Unternehmungsführung, 1996.

Working paper n. 27.

HAGEDOORN, J.

Trends and patterns in strategic technology partnering since the early seventies. Review of Industrial Organization, v. 11, p. 601-616, 1996.

HAGEDOORN, J.;

NARULA, R.

Choosing organizational modes of strategic technology partnering: international and sectoral differences. Journal of International Business Studies, p. 265-284, Second Quarter 1996.

HAMEL, G.

Competition for competence and interpartner learning within international strategic alliances. Strategic Management Journal, v. 12, p. 83-103, 1991.

HARRIGAN, K. R.

Strategic alliance and partner asymmetries. Management International Review, v. 9, p. 5372, Special Issue 1988.

HOBDAY, M.

Innovation in East Asia - the challenge to Japan. London: Edward Elgar, 1995. 
HUBER, G. P.

Organizational learning: the contributing processes and the literatures. Organization Science, v. 2, n. 1, p. 88-115, 1991.

ITAMI, $\mathrm{H}$.

Mobilizing invisible assets. Cambridge, MA: Harvard University Press, 1987.

JOHNSON et al.

Setting the stage for trust and strategic integration in Japanese U.S. co-operative alliances. Journal of International Business Studies, v. 27, n. 5, p. 981-1004, Special Issue 1996.

KLÖTZLE, M.

Die internationale wettbewerbsfähigkeit Brasiliens: eine sektorale analyse. Frankfurt: Peter Lang, 1999.

KOGUT, B.

Joint-ventures: theoretical and empirical perspectives. Strategic Management Journal, v. 9, p. 319-332, 1988.

LANE, P. J.;

LUBATKIN, M.

Relative absorptive capacity and interorganizational learning. Strategic Management Journal, v. 19, p. 461-477, 1998.

LORANGE, P.; ROOS, J.

Alianças estratégicas: forma- ção, implementação e evolução. São Paulo: Atlas, 1996.

MAKRI, M.

Exploring the dynamics of learning alliances. The Academy of Management Executive, v. 13, n. 3, p. 113-114, 1999.

MANO, C.

Metamorfose digital. Exame, São Paulo, v. 34, n. 18, p. 56-58, 2000.

MOWERY, D. C.;

OXLEY, J. E.;

SILVERMAN, B. S.

Technology overlap as interfirm cooperation: implications for the resource-based view of the firm. Research Policy, v. 27, p. 507523, 1998.

NARULA, R.;

HAGEDOORN, J.

Innovating through strategic alliances: moving towards international partnerships and contractual agreements.

Technovation, v. 19, p. 283-294, 1999.

NARULA, R.;

SADOWSKI, B. M.

Technological catch-up and strategic technology partnering in developing countries. International Journal of Technology Management, Summer 1998. 
OSLAND, G. E.;

YAPRAK, A.

Learning through strategic alliances: processes and factors that enhance marketing effectiveness. European Journal of Marketing, v. 29, n. 3, p. 5265, 1995.

RUMELT, R. P.

Towards a strategic theory of the firm. In: LAMB, R. (Org.). Competitive strategic management. Englewood Cliffs, NJ: Prentice-Hall, 1984. p. 556570.

SIM, A. B.;

ALI, Y.

Performance of international joint ventures from developing and $P \& D$ countries: an empirical study in a developing country context. Journal of World Business, v. 33, n. 4, p. 357-370, 1998.

TEECE, D. J.

Competition, cooperation, and innovation: organizational arrangements for regimes of rapid technological progress. Journal of Economic Behavior and Organization, v. 18, p. 1-25, 1992.

TSANG, E. W. K.

A preliminary typology of learning in international strategic alliances. Journal of World Business, v. 34, n. 3, p. 211-226, 1999.

VERGARA, S. C.

Projetos e relatórios de pesquisa em administração. São Paulo: Atlas, 1997.

VONORTAS, N. S.;

SAFIOLEAS, S. P.

Strategic alliances in information technology and developing country firms: recent evidence. World Development, v. 25, n. 5, p. 657680, 1997.

WERNERFELT, B.

A resource-based view of the firm. Strategic Management Journal, v. 5, p. 171-180, 1984. 